\title{
References
}

1. Kallio-Kokko H, Uzcategui N, Vapalahti O, Vaheri A. Viral zoonoses in Europe. FEMS Microbiol Rev. 2005;29:1051-77. http://dx.doi.org/10.1016/j.femsre.2005.04.012

2. European Centre for Disease Prevention and Control. Hantavirus infection. Annual epidemiological report for 2016 [cited 2019 June 20]. https://ecdc.europa.eu/sites/portal/files/documents/ hantavirus-infection-annual-epidemiological-report-2016.pdf

3. Świtaj K, Kajfasz P, Kurth A, Nitsche A. Cowpox after a cat scratch-case report from Poland. Ann Agric Environ Med. 2015;22:456-8. http://dx.doi.org/10.5604/12321966.1167713

4. Grzybek M, Bajer A, Bednarska M, Al-Sarraf M, Behnke-Borowczyk J, Harris PD, et al. Long-term spatiotemporal stability and dynamic changes in helminth infracommunities of bank voles (Myodes glareolus) in NE Poland. Parasitology. 2015;142:1722-43. http://dx.doi.org/10.1017/S0031182015001225

5. Hedman K, Vaheri A, Brummer-Korvenkontio M. Rapid diagnosis of hantavirus disease with an IgG-avidity assay. Lancet. 1991;338:13536. http://dx.doi.org/10.1016/0140-6736(91)92235-T

6. Kallio-Kokko H, Laakkonen J, Rizzoli A, Tagliapietra V, Cattadori I, Perkins SE, et al. Hantavirus and arenavirus antibody prevalence in rodents and humans in Trentino, Northern Italy. Epidemiol Infect. 2006;134:830-6. http://dx.doi.org/10.1017/S0950268805005431

7. Pelkonen PM, Tarvainen K, Hynninen A, Kallio ERK, Henttonen K, Palva A, et al. Cowpox with severe generalized eruption, Finland. Emerg Infect Dis. 2003;9:1458-61. http://dx.doi.org/10.3201/ eid0911.020814

8. Sadkowska-Todys M, Dudek-Godeau D, Kamińska S, BaumannPopczyk A, Czerwiński M, Kucharczyk B, et al. Occurrence and maintenance of hantavirus infections among rodent populations in their natural habitat — results of a field study from Podkarpackie Province, Poland 2010-2012. Przegl Epidemiol.2015; 69:283-8, 395-9.

9. Han BA, Schmidt JP, Bowden SE, Drake JM. Rodent reservoirs of future zoonotic diseases. Proc Natl Acad Sci U S A. 2015; 112:7039-44. http://dx.doi.org/10.1073/pnas.1501598112

Address for correspondence: Maciej Grzybek, Medical University of Gdansk, Department of Tropical Parasitology, Powstania Styczniowego 9B, 81-519 Gdynia, Poland; email: maciej.grzybek@gumed.edu.pl

\section{Polio-Like Manifestation of Powassan Virus Infection with Anterior Horn Cell Involvement, Canada}

\section{Christopher Picheca, ${ }^{1}$ Vignan Yogendrakumar, ${ }^{1}$ James I. Brooks, Carlos Torres, Elizabeth Pringle, Jocelyn Zwicker}

Author affiliation: University of Ottawa, Ottawa, Ontario, Canada

DOI: https://doi.org/10.3201/eid2508.190399

${ }^{1}$ These first authors contributed equally to this article.
Evidence of spinal cord involvement in Powassan virus infection is largely limited to mouse models. We report a case of a polio-like illness caused by Powassan virus infection in a 62-year-old man in Canada. Magnetic resonance imaging showed T2 hyperintensities in the anterior horns of the cervical spinal cord.

$\mathrm{P}$ owassan virus (POWV) is a tickborne flavivirus, named after Powassan, Ontario, Canada, the location of the first documented human infection in 1958 (1). Since then, $\approx 150$ cases of POWV infection have been reported globally, and incidence has increased over time. A total of 125 POWV cases have been identified since 2008, 33 (26\%) in 2017 (2). In Canada, most reported POWV infections have been in the Great Lakes region. A small number of cases have been reported in the Maritime provinces (3).

POWV is transmitted by members of the Ixodes genus of ticks, including I. cookei and the more opportunistic and aggressive I. scapularis. POWV has 2 lineages; lineage 2 (deer tick virus) has emerged quickly in parts of North America, along with the expanding range of I. scapularis ticks.

POWV infection typically begins with prodromal symptoms including fever, nausea, headache, and myalgia. Central nervous system involvement includes an altered level of consciousness, paralysis, or ophthalmoplegia (4). POWV encephalitis has a $10 \%$ mortality rate, and $\leq 50 \%$ of survivors suffer residual deficits (5). Studies with mice have demonstrated that POWV can affect motor neurons in the anterior horns of the spinal cord (6). These same neurons are affected by poliovirus, West Nile virus, and enterovirus D68 (7). However, POWV infection with cord involvement in humans is not well documented; 1 human case demonstrated motor neuron pathology after POWV lineage 2 infection (8), and a second case with suspected motor neuronopathy was reported in 2018 (9).

We present the case of a 62-year-old man living in urban Ontario who experienced nausea, vomiting, and abdominal pain while vacationing in rural Newfoundland. He sought treatment at a hospital in Nova Scotia and experienced diplopia and ataxia. A computed tomography scan of the head did not show any acute intracranial event.

The patient became febrile and experienced dysarthria, weakness, and respiratory distress. Cerebrospinal fluid analysis showed pleocytosis $\left(159 \times 10^{6}\right.$ total nucleated cells: $42 \%$ neutrophils, $43 \%$ lymphocytes) and elevated protein levels $(0.79 \mathrm{~g} / \mathrm{L})$. He was started on empiric treatment with ceftriaxone, ampicillin, acyclovir, and dexamethasone. Results of tests for Cryptococcus, HIV, syphilis, Lyme disease, herpes simplex viruses 1 and 2 , varicella zoster virus, and acid-fast bacilli were negative. Initial arbovirus serology results were negative. The patient worsened, requiring intubation and transfer to an intensive care unit. 


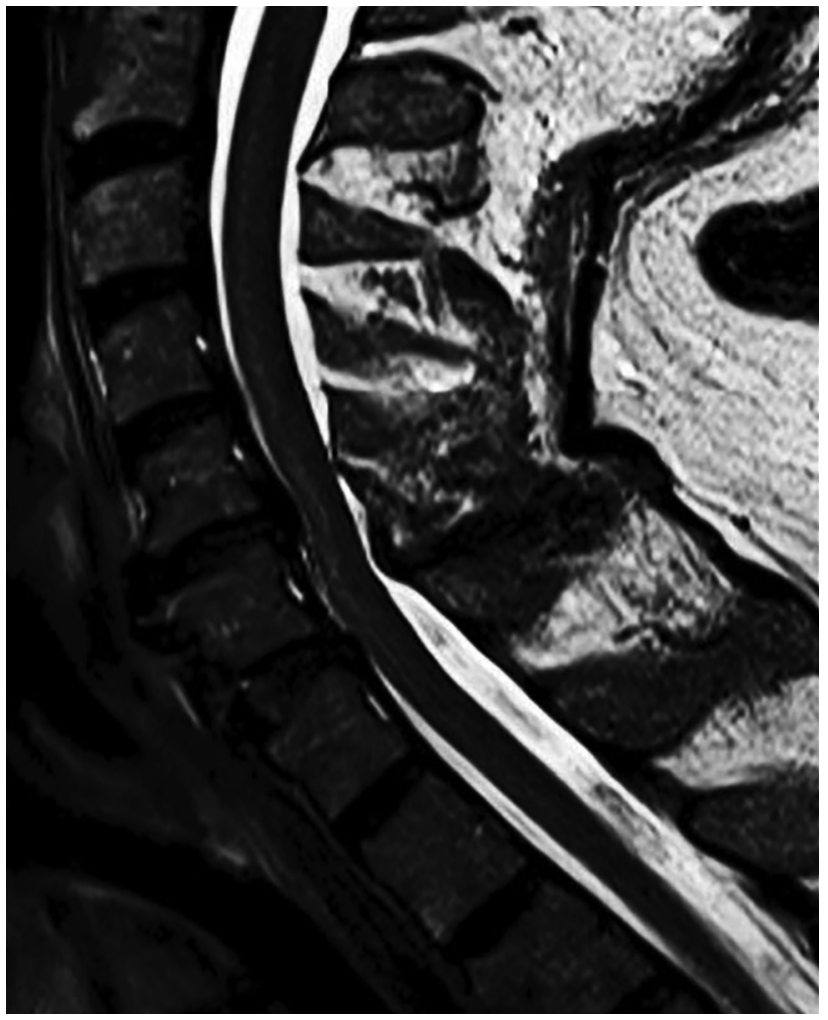

Figure. Sagittal T2-weighted image of cervical spinal cord in a patient with Powassan virus infection, Canada. A longitudinal hyperintensity of the anterior horn is visible from C3 to C6.

Seven days after arriving at the hospital, the patient was unable to lift his arms and was transferred to a tertiary center in Ottawa, Ontario (The Ottawa Hospital). Neurologic exam showed facial and extraocular muscle weakness. He had flaccid tone and absent power in his upper extremities and reduced strength in his lower extremities. Sensation was preserved. Nerve conduction studies demonstrated diffusely low motor amplitudes, normal sensory amplitudes, and normal conduction velocities suggestive of a motor neuronopathy. Electromyography in the acute phase was not possible due to poor patient cooperation.

Results of paired convalescent arbovirus serology collected 1 month after symptom onset were positive. Testing at the National Microbiology Laboratory confirmed POWV infection (hemagglutination inhibition titer 1:80, plaque-reduction neutralization titer 1:160). Magnetic resonance imaging (MRI) of the brain showed infratentorial and supratentorial leptomeningeal enhancement. An MRI of the cervical spine showed increased T2-weighted signal involving the anterior horns from C3 to C6 (Figure; Appendix Figure, https://wwwnc.cdc.gov/EID/article/25/8/190399-App1.pdf).

Follow-up MRI of the brain and spine 1 month later showed interval resolution of leptomeningeal abnormalities, but abnormal signal within the anterior horn of the cervical spine remained. Electrodiagnostic testing repeated 6 months after symptom onset again showed normal sensory nerve conduction studies and abnormal motor nerve conduction studies. There was diffuse denervation in all cervical myotomes including the paraspinal muscles, confirming a motor neuronopathy consistent with a poliomyelitis-like presentation of POWV. We suspect that initial arbovirus serology was performed too early in the disease course, because paired serology 4 weeks later demonstrated seroconversion and confirmed diagnosis.

Our case shares similarities with a recently published report of POWV infection (9). In that case, a patient vacationing in the Luskville region of Quebec, Canada, experienced cranial nerve pathologies and flaccid weakness of the upper extremities. Electrodiagnostic testing showed evidence of diffuse denervation and reinervation across multiple myotomes that was consistent with a motor neuronopathy. Imaging of the brain showed only mild hyperintensities that would not account for the patient's disproportionate weakness. A spinal MRI was not performed. As in our case, acute arbovirus serology results were initially negative but were positive in paired testing (9).

The incidence of POWV infection has increased since 2017 (7). I. scapularis ticks and deer tick virus may be becoming more widely disseminated in northern regions, potentially due to warming climates, whereas infection with prototypical POWV transmitted by I. cookei ticks remains rare and stable in distribution (10). It is possible that Canada will see an increasing number of cases similar to ours. Our findings emphasize the need to include POWV infection in the differential diagnosis for patients with polio-like symptoms in tick-endemic regions.

\section{About the Author}

Dr. Picheca and Dr. Yogendrakumar are resident physicians specializing in neurology at the University of Ottawa. Dr. Picheca has an interest in infectious diseases. Dr. Yogendrakumar's primary research interests are in stroke and intracerebral hemorrhage.

\section{References}

1. McLean DM, Donohue WL. Powassan virus: isolation of virus from a fatal case of encephalitis. Can Med Assoc J. 1959;80: 708-11.

2. Centers for Disease Control and Prevention. Statistics \& maps: Powassan virus. 2018 [cited 2019 Mar 13]. https://www.cdc.gov/ powassan/statistics.html

3. Corrin T, Greig J, Harding S, Young I, Mascarenhas M, Waddell LA. Powassan virus, a scoping review of the global evidence. Zoonoses Public Health. 2018 [cited 2019 Mar 13]. http://dx.doi.org/10.1111/zph.12485

4. Sung S, Wurcel AG, Whittier S, Kulas K, Kramer LD, Flam R, et al. Powassan meningoencephalitis, New York, New York, USA. Emerg Infect Dis. 2013;19. http://dx.doi.org/10.3201/ eid1909.121846 
5. Ebel GD. Update on Powassan virus: emergence of a North American tick-borne flavivirus. Annu Rev Entomol. 2010;55: 95-110. http://dx.doi.org/10.1146/annurev-ento-112408-085446

6. Santos RI, Hermance ME, Gelman BB, Thangamani S. Spinal cord ventral horns and lymphoid organ involvement in Powassan virus infection in a mouse model. Viruses. 2016;8:220. http://dx.doi.org/ $10.3390 / \mathrm{v} 8080220$

7. Hermance ME, Thangamani S. Powassan virus: an emerging arbovirus of public health concern in North America. Vector Borne Zoonotic Dis. 2017;17:453-62. http://dx.doi.org/10.1089/ vbz.2017.2110

8. Tavakoli NP, Wang H, Dupuis M, Hull R, Ebel GD, Gilmore EJ, et al. Fatal case of deer tick virus encephalitis.
N Engl J Med. 2009;360:2099-107. http://dx.doi.org/10.1056/ NEJMoa0806326

9. Sanderson M, Lindsay LR, Campbell TM, Morshed M. A case of Powassan encephalitis acquired in southern Quebec. CMAJ. 2018;190:E1478-80. http://dx.doi.org/10.1503/cmaj.180905

10. Fatmi SS, Zehra R, Carpenter DO. Powassan virus - a new reemerging tick-borne disease. Front Public Health. 2017;5:342. http://dx.doi.org/10.3389/fpubh.2017.00342

Address for correspondence: Vignan Yogendrakumar, The Ottawa Hospital, Civic Campus, 1053 Carling Ave, Ottawa, ON K1Y 4E9, Canada; email: vyogendrakumar@toh.ca

\section{etymologia}

\section{Poliomyelitis [pō'-lē-ō-mī-ə-lī-'təs]}

\section{Ronnie Henry}

$\mathrm{F}$ rom the Greek polios ("gray") + myelos ("marrow"), poliomyelitis may have plagued humanity since antiquity. The funerary stele of the Egyptian priest Ruma (circa 1400 BCE) shows a shortened, withered leg, in what is believed to be one of the earliest depictions of polio. The first clinical description was in 1789 by Michael Underwood. Karl Landsteiner and Erwin Popper identified poliovirus in 1908, and 40 years later John Enders, Thomas Weller, and Frederick Robbins were able to grow poliovirus in tissue culture cells, work for which they received the Nobel Prize in Medicine or Physiology in 1954. This breakthrough facilitated vaccine research, and the first inactivated polio vaccine, developed by Jonas Salk and his team, was licensed in 1955. Six years later, Albert Sabin and his team developed a live, attenuated oral polio vaccine.

Because broad immunization campaigns made progress toward regional polio elimination in the Americas, in 1988 the World Health Assembly declared a goal of global polio eradication. Through a partnership between Rotary International, the World Health Organization, the United Nations Children's Fund, the Centers for Disease Control and Prevention, and the Bill \& Melinda Gates Foundation, the Global Polio Eradication Initiative has achieved a $99.9 \%$ decrease in the global incidence of polio. Today, wild poliovirus transmission occurs in only Afghanistan and Pakistan, and 4 of the 6 World Health Organization

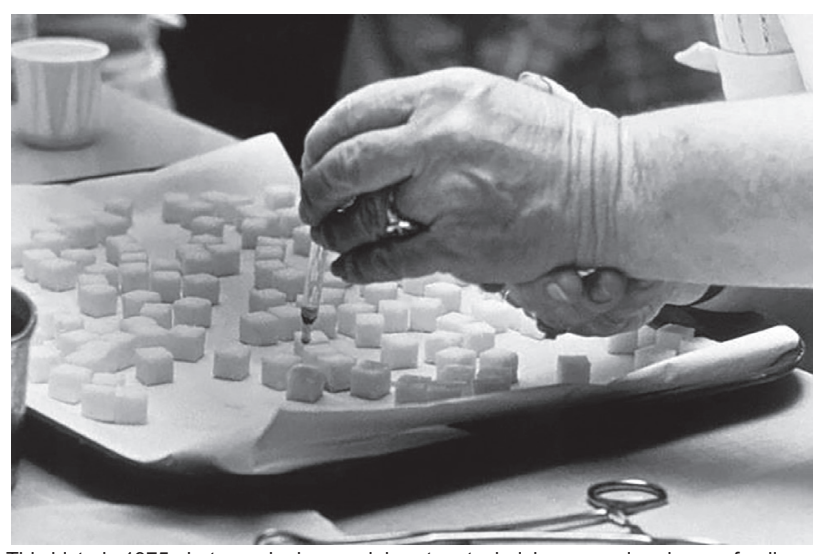

This historic 1975 photograph shows a laboratory technician preparing doses of polio vaccine by placing a liquid droplet of the vaccine on each of these sugar cubes, which would subsequently be ingested orally by each recipient. Photo: Public Health Image Library, Centers for Disease Control and Prevention, 1975.

regions have formally declared the elimination of the indigenous wild poliovirus. Of the 3 types of poliovirus, type 2 wild poliovirus was declared eradicated globally in 2015, and type 3 wild poliovirus has not been detected since 2012 . With only 33 cases globally from type 1 wild poliovirus in 2018 , the task remains to eliminate polio in its last niches.

\section{Sources}

1. Pearce JM. Poliomyelitis (Heine-Medin disease). J Neurol Neurosurg Psychiatry. 2005;76:128. https://doi.org/10.1136/ jnnp.2003.028548

2. Global Polio Eradication Initiative. History of polio [cited 2019 Jun 21]. http://polioeradication.org/polio-today/history-of-polio

3. Global Polio Eradication Initiative. Our mission [cited 2019 Jun 21] http://polioeradication.org/who-we-are/our-mission

Address for correspondence: Ronnie Henry, Centers for Disease Control and Prevention, 1600 Clifton Rd NE, Mailstop E28, Atlanta, GA 30329-4027, USA; email: boq3@cdc.gov 